\title{
Percepção e experiência na filosofia de Berkeley
}

\author{
Pablo Enrique Abraham Zunino \\ Orientador: Prof. Dr. Franklin Leopoldo e Silva \\ FAPESP/USP
}

"A estimativa que fazemos da distância de objetos parece ser um ato do juízo mais baseado na experiência que nos sentidos".

\section{Introdução}

Este texto pretende mostrar o papel que a experiência desempenha na teoria da percepção de Berkeley, tomando como exemplo a percepção da distância. A análise desse problema nos permitirá compreender a relação entre percepção e experiência na formulação de toda sua filosofia.

Podemos caracterizar o núcleo da teoria do conhecimento de Berkeley por uma peculiar identificação entre idéia e objeto sensível: diferentes idéias, enquanto percepções, afetam ao mesmo tempo nossos sentidos para constituírem aquilo que chamamos objetos reais.

Pela vista tenho idéias de luzes e cores, e respectivos tons e variantes. Pelo tato percebo o áspero e o macio, quente e frio, movimento e resistência, e de todos estes a maior ou menor quantidade ou grau. O olfato fornece-me aromas, o paladar sabores, e o ouvido traz ao espírito os sons na variedade de tom e composição. E, como vários

BERKELEY, George. An essay towards a new theory of vision, $\S 3$ in: The works of George Berkeley Bishop of Cloyne. Ed. Luce and Jessop. Nendeln / Liechtenstein: Kraus Reprint, 1979. 
deles se observam em conjunto, indicam-se por um nome e consideram-se uma coisa. Por exemplo, um certo sabor, cheiro, cor, forma e consistência observados juntamente são tidos como uma coisa, significada pelo nome 'maçã'. Outras coleções de idéias constituem uma pedra, uma árvore, um livro, etc. ${ }^{2}$

Desta maneira, Berkeley concebe uma transformação de idéias em objetos ${ }^{3}$ donde todas as coisas (objetos) que nos rodeiam se constituem como feixes de percepções:

Por objeto sensível entendo aquilo que é propriamente percebido pelos sentidos. Coisas propriamente percebidas pelos sentidos são imediatamente percebidas. (...) Os objetos dos sentidos, sendo coisas imediatamente percebidas, são entretanto chamados de idéias. ${ }^{4}$

Ainda que esse tipo de idéias seja a que mais nos interessa, é conveniente observar a classificação de idéias estabelecida por Berkeley, fazendo uma distinção apropriada para o desenvolvimento posterior do trabalho:

É evidente a quem investiga o objeto do conhecimento humano haver idéias (1) atualmente impressas nos sentidos, ou (2) percebidas considerando as paixões e operações do espírito, ou finalmente (3) formadas com o auxílio da memória e da imaginação, compondo, dividindo, ou simplesmente representando as originariamente apreendidas pelo modo acima referido. ${ }^{5}$

A partir dessa classificação distinguimos dois grupos mais gerais levando em conta a maneira como as idéias são percebidas: direta ou indiretamente. As idéias do tipo 1 e 2 são consideradas percepções diretas por tratar-se de apresentação de idéias, enquanto as do tipo 3 são percepções indiretas, isto é, representações. A originalidade de Berkeley

2 Idem. A treatise concerning the principles of human knowledge, $\S 1$ in: Works.

3 GUÉROULT, Martial. Berkeley, quatre études sur la perception et sur Dieu. Montaigne: Aubier, 1956.

4 BERKELEY. The theory of vision vindicated and explained, §§ 9-11 in: Works.

5 Idem. Principles, § 1. 
consiste na concepção de idéias-objeto, isto é, coisas que não precisam ser duplicadas em idéias mentais como cópias de objetos exteriores: as próprias idéias mentais são percepções que, unidas pela experiência $\mathrm{e}$ com ajuda das convenções da linguagem (nomes), tornam-se objetos (sensíveis) como mesas, canetas, livros e assim por diante.

Por outro lado, as idéias de representação são aquelas que temos em ausência da percepção direta, ou seja, quando lembramos ou imaginamos coisas a partir das percepções diretas que tivemos:

Acho que tenho a faculdade de imaginar, conceber ou representarme para mim mesmo as idéias dessas coisas particulares que já percebi, compondo-as e dividindo-as de vários modos. Posso imaginar um homem com duas cabeças, ou a parte superior de um homem unida com o corpo de um cavalo. ${ }^{6}$

Tanto o senso comum quanto a maioria dos filósofos concorda com Berkeley quando diz que esse tipo de idéias existe apenas na mente que as percebe, no entanto ao primeiro grupo de idéias (maçãs, pedras, árvores, etc.) é negada essa condição ontológica. Para eles, esses objetos existem fora da mente, isto é, num espaço exterior.

Antes de nos aprofundarmos nessa questão, preferimos examinar a classificação de idéias com base nos comentadores ${ }^{7}$ e nos filósofos que, provavelmente, tenham inspirado o próprio Berkeley. Para as idéias do primeiro tipo - atualmente impressas nos sentidos - Berkeley parece valer-se da noção aristotélica de sensível próprio, ${ }^{8}$ na medida em que nossos sentidos têm em potência as propriedades que os objetos têm em ato, portanto, os objetos atualizam as propriedades quando são percebidos pelos sentidos. As expressões utilizadas por Berkeley quando se refere a esse tipo de idéias são: "atualmente", "imediatamente" e "propriamente" percebidas pelos sentidos ou impressas nos sentidos.

6 Idem. First draft of the Introdution to the Principles, $\S 10$ in: Works.

7 WINKLER, Kenneth. Berkeley: An interpretation, 6, 2, p.154-5. Oxford: Clarendon Press, 1994.

8 ARISTÓTELES. Acerca del alma, II, vi, p.189. Madrid: Gredos, 1988. 
As idéias do segundo tipo - percebidas considerando as paixões e operações do espírito - não são enumeradas por Berkeley, mas pensamos que essa classificação teve alguma inspiração lockeana. Com efeito, Locke denomina idéias de sensação às qualidades sensíveis e idéias de reflexão às operações que

suprem o entendimento com outra série de idéias que não poderia ser obtida das coisas externas, tais como a percepção, o pensamento, o duvidar, o crer, o raciocinar, o conhecer, o querer e todos os diferentes atos de nossas próprias mentes. (...) O termo operações é usado aqui em sentido lato, compreendendo não apenas as ações da mente sobre suas idéias, mas também certos tipos de paixões que às vezes nascem delas, tais como a satisfação ou inquietude que nascem de qualquer pensamento. ${ }^{9}$

A percepção direta, portanto, pode ser uma cor, um som, um cheiro, um sabor ou qualquer sensação experimentada na pele como textura ou solidez (idéias do tipo 1); também pode ser uma dúvida ou uma vontade repentina (idéias do tipo 2) e, finalmente, pode ser um conjunto de percepções que, pela experiência, apreendemos a identificar com determinados nomes todas as vezes que o percebemos, por exemplo, maçã (somatória de idéias do tipo 1 - percebidas em conjunto com ajuda da experiência). Entretanto, a percepção indireta pode ser caracterizada pelas representações ou pelas idéias do tipo 3 formadas com o auxílio da memória e da imaginação - por exemplo, quando pensamos em uma maçã, uma sereia, etc. Cabe notar que a representação pode ser de um objeto possível (maçã) ou não (sereia). O que importa é distinguir a percepção direta da percepção indiréta.

Todavia, existe outro tipo de percepção indireta que Grayling menciona ao comentar uma passagem dos Diálogos de Berkeley:

Isso, portanto, é a substância principal da teoria berkeleyana sobre a percepção sensível. O princípio básico é resumido para Berkeley por

9 LOCKE, John. Ensaio acerca do entendimento humano, II, i, 4, p. 28 in: Os Pensadores. São Paulo: Nova Cultural, 1991. 
Hylas: "na verdade, os sentidos não percebem nada que eles não percebam imediatamente: porque eles não fazem inferências" ${ }^{10}$ Mas em adição à percepção sensível imediata existem, na visão de Berkeley, dois caminhos mediatos [ou indiretos] para o conhecimento; um é a inferência, o outro é a percepção sensível envolvendo o que Berkeley chama de "sugestão" É essa segunda categoria a que tem levantado o desentendimento entre os comentadores."

Berkeley, para evitar qualquer confusão, separa aquilo que pertence à percepção e que, portanto, é próprio dos sentidos - ainda que de maneira indireta - do que pertence ao entendimento: "Perceber é uma coisa; ajuizar é outra. Da mesma maneira, ser sugerido é uma coisa, e ser inferido é outra. As coisas são sugeridas e percebidas pelos sentidos. Nós produzimos juízos e inferências pelo entendimento" 12

\section{A Teoria da Visão}

Nos parágrafos anteriores vimos como as idéias-objeto concebidas por Berkeley se constituem mentalmente como feixe de percepções, tornando desnecessário o espaço exterior que contém os objetos que vemos e tocamos. Isto não é admitido pela maioria dos filósofos, nem pelo senso comum que, segundo Berkeley, alega a seguinte objeção:
(...) vemos coisas fora de nós ou à distância que, portanto, não exis- tem na mente; sendo absurdo que essas coisas vistas a uma distância de várias milhas, estejam tão perto de nós quanto nossos próprios pensamentos. ${ }^{13}$

Segundo Tipton, ${ }^{14}$ Berkeley tem dois argumentos para tratar essa objeção. O primeiro ele o estabelece sucintamente: "Em resposta

${ }^{10}$ BERKELEY. Three dialogues between Hylas and Philonous, I, p. 174 in: Works.

${ }^{11}$ GRAYLING, A. C. Berkeley: the central arguments, II, ii, p. 63. Illinois: Open Court, 1986.

12 BERKELEY. Theory of vision vindicated, $\S 42$.

${ }^{13}$ Idem. Principles, $§ 42$.

${ }^{14}$ TIPTON, I. C. Berkeley: the philosophy of imaterialism, VI, iv, p. 201. New York \& London: Garland, 1988. 
a isso, desejo que se considere, que em sonhos muitas vezes percebemos coisas existindo a uma grande distância de nós, e ainda assim, se reconhece que essas coisas têm sua existência apenas na mente" 15

Para o segundo argumento ele apela para a Nova teoria da visão:

Mas para o completo esclarecimento deste ponto, deve-se dedicar un bom tempo à consideração de como é que percebemos a distância e as coisas situadas à distância pela vista. Porque a verdade de que deveríamos ver o espaço exterior, e os corpos realmente existindo nele, alguns mais perto, outros mais afastados, parece carregar uma oposição com o que foi dito, de sua existência em qualquer lugar sem a mente. A consideração desta dificuldade foi o que deu à luz meu Essay towards a new theory of vision, publicado não há muito tempo. Onde é mostrado que a distância ou exterioridade não é imediatamente nem por si mesma percebida pela visão, nem ainda apreendida ou ajuizada por linhas ou ângulos, ou qualquer coisa que tenha uma conexão necessária com ela: senão que é apenas sugerida aos nossos pensamentos, por certas idéias visíveis e sensações associadas com a visão, as quais em sua própria natureza não têm nenhum tipo de similitude ou relação, nem com a distância, nem com as coisas situadas à distância. Mas por uma conexão ensinada pela experiência, vêm a significar e sugeri-las a nós, da mesma maneira que as palavras de uma linguagem sugerem as idéias que supõem significar. Tanto que um homem cego de nascença, depois de adquirir a visão, não pensaria, à primeira vista, que as coisas que ele via, existiam sem sua mente, ou a uma distância dele. ${ }^{16}$

Em outras palavras e para resumir tudo o que precede, devemos, num primeiro momento, procurar entender como se constituem as relações espaciais para Berkeley, pensando que a distância "tornase visível por meio de alguma outra idéia que é por si mesma imediatamente percebida no ato da visão" 17

\footnotetext{
${ }^{15}$ BERKELEY. Principles, $§ 42$.

${ }^{16}$ Idem, ibidem, § 43.

${ }^{17}$ Idem. Essay, § 11.
} 


\section{0 problema de Molyneux}

Para Berkeley, a expressão 'ver a distância' é problemática, porque o que é própria e imediatamente percebido pela visão são apenas luzes e cores. Esta questão não é advertida por Locke, para quem a percepção visual da distância é evidente:

(...) julgo desnecessário provar que os homens percebem pela visão certa distância entre corpos de cores diferentes, ou entre as partes do mesmo corpo, do mesmo modo que vêem as próprias cores e podem obviamente senti-las no escuro pelo sentido do tato. ${ }^{18}$

Para caracterizar o problema da percepção visual da distância, tomaremos como ponto de partida um argumento comum a ambos filósofos, conhecido como o problema de Molineux, que Berkeley cita junto com a resposta de Locke procurando uma confirmação adicional de sua teoria:

Suponhamos um homem cego de nascença, e agora adulto, ensinado pelo seu tato a distinguir entre um cubo e uma esfera do mesmo metal e aproximadamente de igual tamanho, de forma que possa dizer, tocando um ou outro, qual é o cubo e qual a esfera. Suponhamos que o cubo e a esfera se encontrem situados sobre uma mesa e que se faça o cego ver. A questão é se pela vista e antes de tocá-los poderia agora distinguir e dizer qual é o globo, qual o cubo.

Ao que o agudo e judicioso proponente [Molyneux] responde:

Não. Pois, apesar de ter obtido a experiência de como um globo, como um cubo, afetam seu tato, ainda não tinha alcançado a experiência de que o que afeta seu tato de tal e tal forma devia afetar sua vista de tal e tal outra: ou que um ângulo protuberante no cubo que oprimia sua mão desigualmente, deveria aparecer a seu olho como aparecia no cubo. Eu [Locke] concordo com este reflexivo cavalheiro, que tenho orgulho de chamar meu amigo, em sua resposta a este seu problema; e acho que o homem cego, ao ver pela primeira vez,

${ }^{18}$ LOCKE. Ensaio, II, xiii, 2, p. 54. 
não seria capaz de dizer com certeza qual era o globo e qual o cubo, baseando-se apenas naquilo que viu neles. ${ }^{19}$

Berkeley também concorda com a resposta negativa deles [Locke e Molyneux], no entanto utiliza o argumento do cego de nascença com um propósito mais radical, isto é, para mostrar que os objetos percebidos existem apenas na mente e não em um espaço exterior. $O$ mesmo pode ser observado em outro experimento mental aplicado por Philonous nos Diálogos: "Supõe agora que uma de tuas mãos está quente, e a outra fria, e ambas são, ao mesmo tempo, submergidas dentro da mesma vasilha de água, em um estado intermediário; não pareceria que a água está fria para uma mão e morna para a outra?" 20 Dizer que a mesma água está fria e mornàao mesmo tempo é admitir uma contradição, portanto, devemos concordar com Berkeley, para quem o calor e o frio não existem na água e sim na mente que os está percebendo.

A suposição de que um cego, por milagre ou qualquer outro motivo, tenha a possibilidade de ver permite imaginar sensações separadas, isto é, o que é próprio de cada sentido. Desta maneira podemos separar o que vemos daquilo que tocamos e entender porque, para Berkeley, as idéias-objeto estão no espírito (mente) e não em um espaço exterior ou à distância alguma:

(...) um homem cego de nascença, a quem se lhe fizesse ver, não teria, nesse primeiro instante, idéia da distância pela vista; o sol e as estrelas, os objetos mais remotos como os mais próximos, todos pareceriam estar no seu olho, ou melhor, na sua mente. Os objetos percebidos pela vista lhe pareceriam (como são na verdade) não outra coisa que uma nova série de pensamentos ou sensações, sendo cada um deles tão próximo quanto as percepções de dor ou prazer, ou as mais íntimas paixões da sua alma. ${ }^{21}$

\footnotetext{
${ }^{19}$ BERKELEY. Essay, § 132. (Locke. Ensaio, II, ix, 8).

${ }^{20}$ Idem. Dialogues, I, p. 178-9.

${ }^{21}$ Idem. Essay, § 41.
} 
Cabe destacar que, muitos anos depois, Berkeley confirmou sua teoria, com as descrições acerca de uma pessoa cega desde sua infância, que recuperou a visão por meio de uma intervenção cirúrgica: "Quando ele viu por primeira vez, estava tão longe de realizar qualquer juízo acerca de distâncias que pensou que todos os objetos tocavam seus olhos (como ele o expressou) da maneira como ele sentia na pele; e pensou que nenhum objeto era tão agradável como esses que eram lisos e regulares, pensou que não poderia formular nenhum juízo sobre sua forma, ou adivinhar o que era que lhe estava agradando nesses objetos. Ele não conhecia a forma de nada, nem distinguia uma coisa de outra, por mais que fossem diferentes em forma ou tamanho; mas sendo avisado de que coisas se tratava, cujas formas ele conhecia anteriormente pelo tato, observou cuidadosamente que podia conhecê-las novamente; mas havendo tantos objetos para apreender de uma vez, esqueceu a maior parte deles. E (como ele mesmo disse) ao princípio ele aprendeu a conhecer, e novamente esqueceu, um milhar de coisas por dia. Várias semanas depois ele estava deitado, sendo enganado por fsiguras, perguntando qual era o sentido mentiroso: o tato ou a visão?" 22

\section{A Solução de Berkeley}

A óptica geométrica - vigente na época de Berkeley - explicava a percepção da distância a partir da concepção matemática de espaço homogêneo, de nítida inspiração cartesiana. Descartes distingue seis qualidades principais que nós percebemos entre os objetos da visão: "a luz, a cor, a posição, a distância, o tamanho e a forma" ${ }^{23}$ Berkeley as reduziria a luz e cor, recusando todas as teorias baseadas na geometria, que podemos agrupar em duas concepções bastante gerais. A primeira, considerando que vemos a distância somente com os dois olhos, consiste em estabelecer uma relação entre a distância e

${ }^{22}$ Idem. Theory of vision vindicated, $\$ 71$.

${ }^{23}$ DESCARTES, René. La dioptrique, VI, p. 699-700. In: Oeuvres Philosophiques. Paris: Garnier, 1963. 
o ângulo formado pelos eixos ópticos: quanto mais agudo é o ângulo, maior será a distância. A segunda concepção supõe que podemos ver a distância apenas com um olho, sendo a amplitude da incidência dos raios na pupila que determinará a distância: quanto maior for a divergência com a qual incidem os raios na pupila, menor será a distância; quanto mais paralelos os raios incidem, mais distante o objeto se encontra (chegando até o infinito em caso de paralelismo).

A solução de Berkeley para este problema pode ser explicada por meio do que Pitcher ${ }^{24}$ chama 'guias de distância', isto é, sensações às quais associamos a percepção da distância. Devido a uma conexão habitual estabelecemos relações entre essas idéias experimentadas em nossos olhos e a distância correspondente a cada modificação sensível. Berkeley aponta para uma disposição dos olhos reduzindo ou ampliando o espaço entre as pupilas que ocasiona uma confusão da aparência ou tensão nos olhos. De qualquer maneira, a experiência é a única responsável por esta associação, já que "nenhuma delas [sensações] têm, em sua própria natureza, relação ou conexão alguma com a distância, sendo impossível que signifiquem os diversos graus desta, a não ser que pela experiência tenham sido conectadas a eles" 25

Berkeley conclui que o 'cego', uma vez familiarizado com a percepção visual, começará a estabelecer relações entre as idéias do tato e da vista por meio da experiência: "depois de ter percorrido certa distância medida pelo movimento de seu corpo, o que é perceptível pelo tato, chegará a perceber tais e tais idéias do tato, que têm sido relacionadas ordinariamente com tais e tais idéias visíveis" 26

A analogia com a linguagem é um argumento recorrente que Berkeley utiliza para explicar o fenômeno da percepção visual da distância como percepção indireta. Um pensamento é sugerido pelo som de uma palavra quando percebido pelo ouvido. Esse som é uma per-

${ }^{24}$ PITCHER, George. Berkeley, p. 24-5. México: Fondo de Cultura Económica, 1983.

${ }^{25}$ BERKELEY. Essay, §§ 16-28.

${ }^{26} \mathrm{Idem}$, ibidem, § 45. 
Por sua vez, Bertrand Russell quer mostrar o alcance do seu método lógico-analítico, e também encontra em Berkeley um exemplo:

O ataque de Berkeley, reforçado pela fisiologia dos órgãos dos sentidos, nervos e cérebro, é muito poderoso. Penso que devamos admitir como provável que os objetos imediatos dos sentidos dependem, para sua existência, de nossas condições fisiológicas, e que, por exemplo, as superfícies coloridas que enxergamos deixam de existir quando fechamos os olhos. ${ }^{32}$

Na filosofia da ciência, o pensamento de Berkeley encontra ainda um lugar para ecoar. Segundo Popper, é Ernst Mach quem retoma algumas de suas idéias no campo da filosofia da física: "Ambos acreditavam numa forma de doutrina hoje em dia chamada fenomenalismo - a visão de que as coisas físicas são feixes, ou complexos, ou construtos de qualidades fenomenológicas, de cores, sons, etc. particulares e experimentados. Mach chama-os 'complexos de elementos' A diferença é que para Berkeley, são diretamente causados por Deus. Para Mach, apenas estão aí. Enquanto Berkeley diz que pode não haver nada físico por trás dos fenômenos físicos, Mach sugere que não há nada mesmo por trás deles" ${ }^{33}$

O imaterialismo radical de Berkeley, refutado com um chute pelo Dr. Johnson ${ }^{34}$ e chamado de idealismo dogmático por Kant; ${ }^{35}$ ainda pode ser motivo de pesquisas e sobrevive nas discussões contemporâneas: "O estudo dos mecanismos visuais é propício a uma discussão

32 RUSSELL, Bertrand. Nosso conhecimento do mundo exterior, 3, p. 47. São Paulo: Ed. Nacional, 1966.

${ }^{33}$ POPPER, Karl. "A note on Berkeley as precursor of Mach", p. 34 in: CROMBIE (General Editor). George Berkeley bicentenary. New York \& London: Garland, 1988.

${ }^{34}$ Ante a impossibilidade de refutar a tese berkeleyana de que as coisas existem apenas na mente; ele bateu vigorosamente com o pé numa grande pedra até que recuou dizendo: "refuto-a assim"

${ }^{35}$ KANT, Immanuel. Crítica da razão pura, p. 192 in: Os Pensadores. São Paulo: Nova Cultural, 1999. 
sobre a oportunidade de uma alternativa materialista às concepções atualmente em vigor e sobre as possibilidades de persistência de teorias imateriais" 36

\section{Bibliografia}

ARISTÓTEles. Acerca del alma. Madrid: Gredos, 1988.

Bergson, Henri. "A intuição filosófica", in: Conferências, Os Pensadores. São Paulo: Abril Cultural, 1984.

BERKELEY, George. An essay towards a new theory of vision, in: The works of George Berkeley Bishop of Cloyne. Ed. Luce and Jessop. Nendeln / Liechtenstein: Kraus Reprint, 1979.

. A treatise concerning the principles of human knowledge, in: The works of George Berkeley Bishop of Cloyne. Ed. Luce and Jessop. Nendeln / Liechtenstein: Kraus Reprint, 1979.

. The theory of vision vindicated and explained, in: The works of George Berkeley Bishop of Cloyne. Ed. Luce and Jessop. Nendeln / Liechtenstein: Kraus Reprint, 1979.

. First draft of the Introdution to the Principles, in: The works of George Berkeley Bishop of Cloyne. Ed. Luce and Jessop. Nendeln / Liechtenstein: Kraus Reprint, 1979.

. Three dialogues between Hylas and Philonous, in: The works of George Berkeley Bishop of Cloyne. Ed. Luce and Jessop. Nendeln / Liechtenstein: Kraus Reprint, 1979.

DesCartes, René. La dioptrique, VI, pp. 699-700 in: Oeuvres Philosophiques. Paris: Garnier, 1963.

Grayling, A. C. Berkeley: the central arguments, II, ii, p. 63. Illinois: Open Court, 1986.

GuÉROulT, Martial. Berkeley, quatre études sur la perception et sur Dieu. Montaigne: Aubier, 1956.

KANT, Immanuel. Crítica da razão pura, p. 192 in: Os Pensadores. São Paulo: Nova Cultural, 1999.

${ }^{36}$ MEYER, Philippe. O olho e o cérebro: biofilosofia da percepção visual, p. 124. São Paulo: Ed. UNESP, 2002. 
LOCKE, John. Ensaio acerca do entendimento humano, II, i, 4, p. 28 in: Os Pensadores. São Paulo: Nova Cultural, 1991.

MeYER, Philippe. O olho e o cérebro: biofilosofia da percepção visual, p. 124. São Paulo: Ed. UNESP, 2002.

Prtcher, George. Berkeley, pp. 24-5. México: Fondo de Cultura Económica, 1983.

POPPER, Karl. "A note on Berkeley as precursor of Mach", p. 34 in: CROMBIE (General Editor). George Berkeley bicentenary. New York \& London: Garland, 1988.

Russell, Bertrand. Nosso conhecimento do mundo exterior, 3, p. 47. São Paulo: Ed. Nacional, 1966.

TIPTON, I. C. Berkeley: the philosophy of imaterialism, VI, iv, p. 201. New York \& London: Garland, 1988.

WINKLER, Kenneth. Berkeley: An interpretation, 6, 2, pp.154-55. Oxford: Clarendon Press, 1994. 